\title{
Effects of injection moulding process parameters on impact strength of polypropylene-hydroxyapatite biocomposite
}

\author{
M. Manoraj and M. N. M. Ansari* \\ Center for Advanced Materials, Department of Mechanical Engineering, \\ Universiti Tenaga Nasional, Kajang 43000, Selangor Darul Ehsan, Malaysia \\ *E-mail: ansari@ uniten.edu.my \\ Phone: +603-89212213; Fax: +603-89212116
}

\begin{abstract}
The present work investigates the impact strength of Polypropylene-Hydroxyapatite (PPHA) biocomposite for orthopaedic scaffold implants and tissue engineering applications. The effects of injection pressure and speed and cooling time on the impact strength of polypropylene (PP) - hydroxyapatite (HA) were studied for a wide range of process parameters using injection moulding machine. PP (100 wt $\%)$ was processed using injection moulding machine with optimal process settings. Later, PP (99 wt\%) with HA $(1 \mathrm{wt} \%)$ was melt-mixed using a twin-screw compounding extruder followed by injection moulding process to prepare the impact test specimens with varying process parameters. The impact of strength test was conducted according to ASTM-D 256 standards on PP and PP-HA biocomposites. The fractured samples were studied for morphological properties using scanning electron microscope. The result shows that injection moulding parameters had a great influence on their impact strength and morphological properties. The best conditions to produce composites of optimum mechanical properties are injection pressure of $30 \mathrm{MPa}$, injection speed of $15 \mathrm{cc} / \mathrm{s}$ and cooling time of $20 \mathrm{~s}$ for PPHA biocomposite. It is known that characterising efficient solutions is an important way to realise the potential of an injection moulding operation. Besides that, by applying all various parameters, we are most definitely able to reduce the time of a real-time injection moulding operation and produce a better quality product.
\end{abstract}

Keywords: Polypropylene; hydroxyapatite; injection moulding; impact strength.

\section{INTRODUCTION}

Injection moulding process is the most commonly used processing technology of plastic products. The injection moulding technique is widely used in the process of even complex thermoplastic polymeric articles in high-scale and short-time. Polymer-hydroxyapatite composites have been used as an astounding scaffold for biomedical applications with great biocompatibility and high osteoconductive movement [1]. Sufficient knowledge about mould design and process parameters is required for producing a quality and costeffective product using this technique. However, many injection plastic product manufacturers would rather undergo trial and error at the beginning of manufacturing a new product. Suitable process parameters are required for a new product and play a significant role in achieving a high-quality product with good mechanical properties [2]. These trials and errors are used to get a set of process parameters with higher impact strength and lower shrinkage. Hence, optimised processing conditions can be obtained 
from experimental results using the obtained set of parameters. The first idea of HA reinforced polyethylene composite to be utilised as a bone substitute was conceived and developed by Bonfield [3]. Since then, the mechanical properties of hydroxyapatite (HA) reinforced polyethylene composite have been studied extensively [3]. The blend of bioactive but brittle hydroxyapatite and ductile high-density polyethylene gives decent biocompatibility and sufficient mechanical properties of the composite specimens [4]. Based on hydroxyapatite (HA) reinforced high-density polyethylene (HDPE), an incredible number of polymer matrix bio composites have been proposed. However, the sub-par mechanical properties of these composites restricted their applications as nonloadbearing inserts $[5,6]$. Impact strength is an important factor in defining the quality of injection moulded products. This factor is influenced by the processing parameters governing injection moulding processes as have been shown in many studies. Cambell et al. studied the effect of injection moulding process parameters on the tensile and impact strength of polypropylene and concluded that the processing parameter interactions significantly impacting the part's mechanical properties [7,8].

Inappropriate settings for processing parameters (such as mould temperature, nozzle and barrel temperatures, injection speed and pressure, holding pressure and time, and cooling time) can result in products with weaker impact strength or poor quality [9]. Therefore, determining the appropriate combinations for the processing parameters is imperative for optimising injection moulding operations. Wang et al. [10] examined two methodologies to enhance the interfacial condition in polyethylene-hydroxyapatite composites in altering their mechanical properties: the utilisation of silane treated hydroxyapatite as filler, and the use of polymer uniting for polyethylene. The polypropylene/hydroxyapatite composite was produced using a technique which was utilised for polyethylene-hydroxyapatite [10]. Cunha et al. [11] considered the impact of processing conditions on the mechanical conduct of the HA/UHMWPE composite using injection and compression moulding, and found that the injection moulding procedure guaranteed preferable results over compression moulding because of the serious blending and shearing of the polymer. Ward et al. [12] demonstrated part of pressure annealing in enhancing the firmness of polyethylene/hydroxyapatite composites. In the present work, polypropylene (PP)-hydroxyapatite (HA) composites were developed by twin-screw extruder using blended powder of HA and granules of PP. The combined composites were subjected to heat and pressure in the injection moulding machine and the mechanical properties PP-HA composites were studied.

Among the mechanical properties, impact strength was more affected by processing factors than other mechanical properties. The impact strength of the PP-HA composites is mainly influenced by many factors including matrix intrinsic properties, optimum HA-matrix interaction, HA concentration, HA geometry, HA-matrix stress transfer efficiency, HA orientation, and HA dispersion and distribution [13, 14]. At the same time, the HA bridging, HA pull-outs, crack propagation and matrix deformation mechanisms contribute a vital role in the impact rupture of HA reinforced composites [14, 15]. Many of these mechanisms contribute simultaneously during impact tests which make it complicated to determine the impact strength of the composites. The process flow is described in Figure 1. 


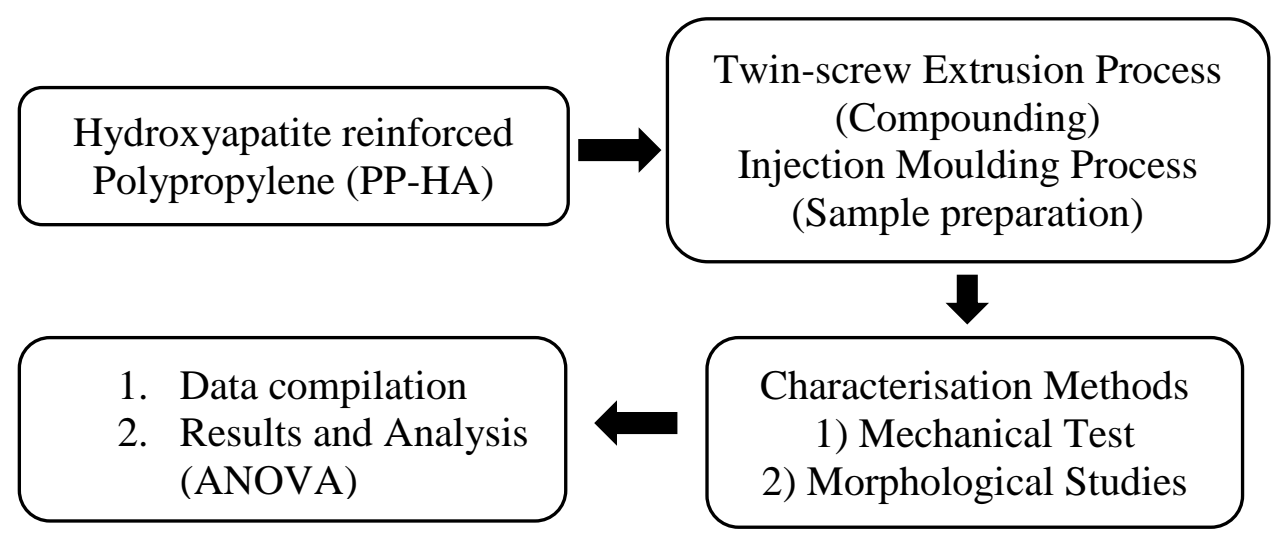

Figure 1. Block diagram of the experimental processes.

\section{METHODS AND MATERIALS}

A commercial polypropylene impact copolymer (TITANPRO SM 840) with melt flow index (MFI) of $0.7 \mathrm{~g} / 10 \mathrm{~min}$ at $2.16 \mathrm{~kg}$ and $230{ }^{\circ} \mathrm{C}$ and Hydroxyapatite (HA) was supplied by M/s.Pultrusion Sdn. Bhd., Malaysia. It has a purity of $99 \%$ and the average particle size is $2-10 \mu \mathrm{m}$. The colour of Hydroxyapatite is white and spherical in shape. Polypropylene granules were melt-mixed and compounded with HA powder using a corotating twin-screw extruder (Nanjing Norda Xinye Extrusion Equipment Co., Ltd: TDS16) with a screw speed of $30 \sim 60 \mathrm{rpm}$ at $200{ }^{\circ} \mathrm{C}$. The filler content (HA) was fixed at $1 \mathrm{wt} \%$ due to its nano-sized particle dimensions. These mixtures were measured based on the formulation (wt.\%) shown in Table 1.

Table 1. The formulation of nanocomposite compounding.

\begin{tabular}{ccc}
\hline Formulation & PP (wt $\%)$ & HA (wt $\%)$ \\
\hline $1(\mathrm{PP})$ & $100 \%$ & $0 \%$ \\
$2(\mathrm{PP}-\mathrm{HA})$ & $99 \%$ & $1 \%$ \\
\hline
\end{tabular}

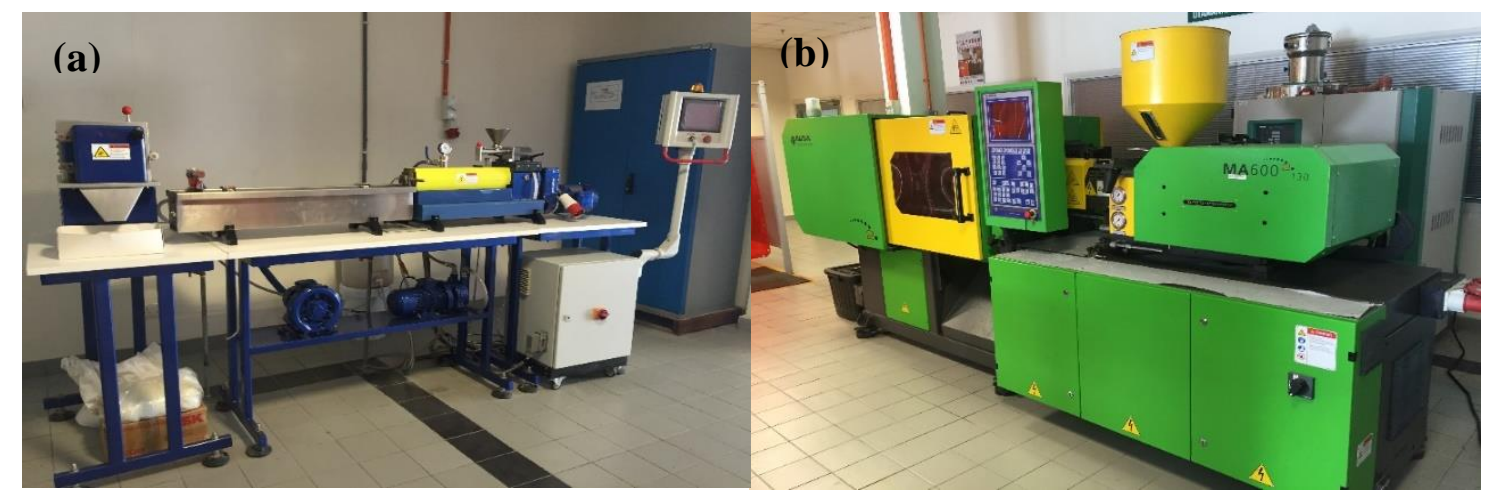

Figure 2. (a) Twin-screw Extruder (Nanjing) (b) Injection Moulding Machine (HAITAN).

After this process, the mixed materials which were in the form of granules were moulded using an Injection Moulding Machine (Figure 2) at $185^{\circ} \mathrm{C}$ and pressures of 30 
and $40 \mathrm{MPa}$ with cooling times of 20 and $40 \mathrm{~s}$ and injection speeds of 15, 25, and $35 \mathrm{cc} / \mathrm{s}$. Each sample was cut to $13 \mathrm{~mm}$ in width and $63 \mathrm{~mm}$ in length. Samples for the impact test were prepared according to ASTM D-256 standards. Four specimens from each pressure, cooling time, and injection speed were tested and the average value was reported. The primary part of the work was concerned with the determination of the impact strength. Zwick/Roell HIT50P was used to perform the notched Izod tests as shown in Figure 3. ASTM D-256 standard was used to test rectangular notched bars for the verification of pendulum impact-testing machines. The impact machine was utilised using the manual clamping vice with a sample adapter accurately positioned in the vice with a centering device adapted for notched specimens and then hindered by turning a hand wheel clockwise. A screw available just in the middle of the hand wheel was used to control the clamping torque applied by means of a dynamometric key with a resolution of $0.5 \mathrm{~N}-\mathrm{m}$ and a working torque range from 1 to $25 \mathrm{~N}-\mathrm{m}$. To dodge undesirable impacts, the research centre where the mechanical properties were measured was conditioned at $23.8^{\circ} \mathrm{C}$ and a $50 \%$ relative moistness. The impact strength was figured by dividing the absorbed energy by the underlying cross-sectional area behind the notch. The normal values were calculated from 10 runs for each sample.

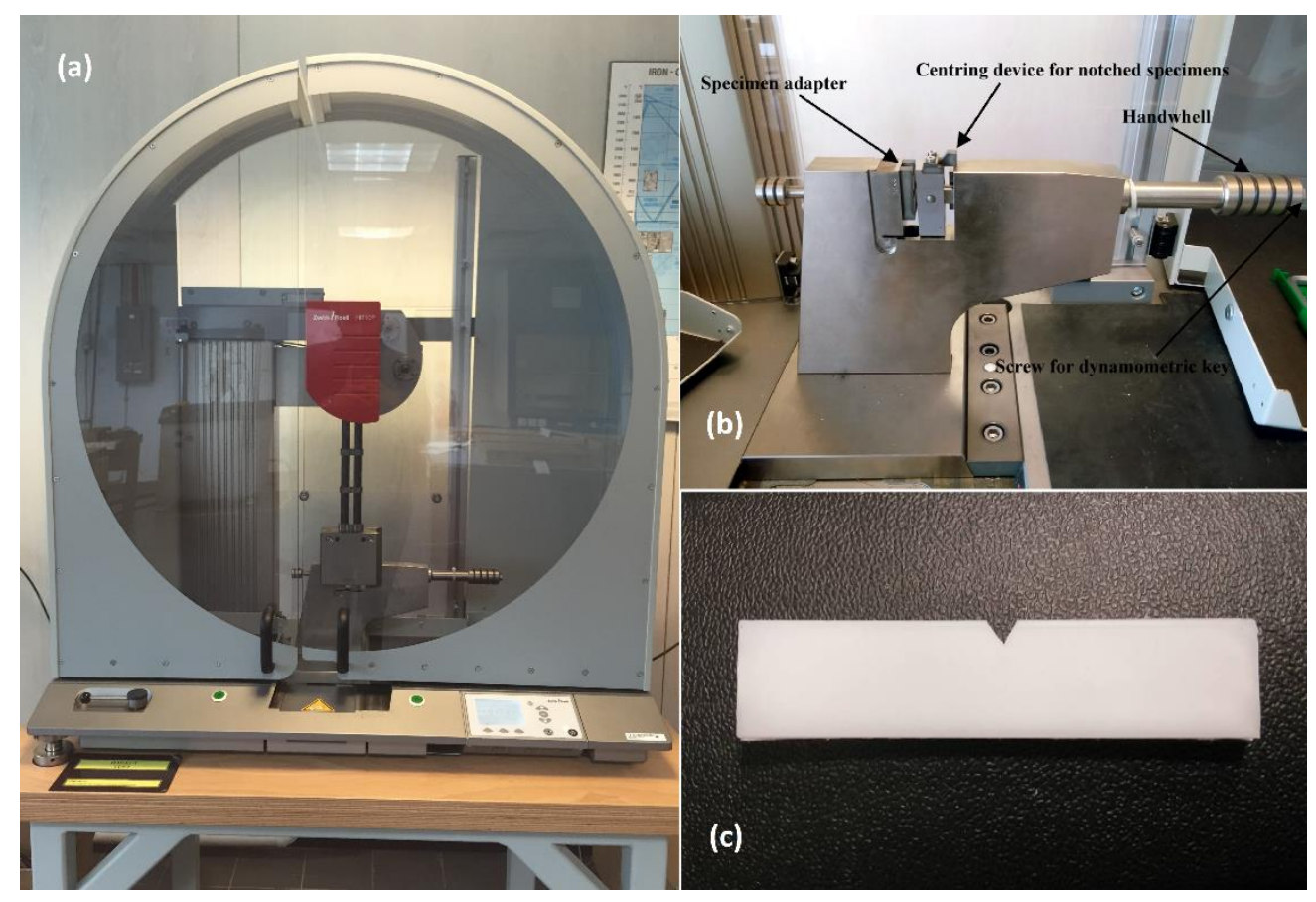

Figure 3. (a) The impact machine (Zwick); (b) Vice-clamp; (c) Impact test specimen.

After this process, the granular compounded materials were moulded at $185{ }^{\circ} \mathrm{C}$ and pressures of 30 and $40 \mathrm{MPa}$ with cooling times of 20 and $40 \mathrm{sec}$ and injection speeds of 15,25 , and $35 \mathrm{cc} / \mathrm{s}$. Each sample was $12.7 \mathrm{~mm}$ in width, $62.5 \mathrm{~mm}$ in length, and 3.2 $\mathrm{mm}$ in thickness. Samples for impact test were prepared according to ASTM D-256 standards. Table 2 shows the design of experiment which consists of five specimens from each pressure, cooling time, and injection speed that were tested and the average value is reported in the next section. The fracture surfaces of the impact test samples were observed using a Jeol S-360 scanning electron microscope (SEM). The configuration was pre-set to meet the optimised level of results. 
Table 2. Design of experiment.

\begin{tabular}{cccc}
\hline $\begin{array}{c}\text { No. of } \\
\text { Experiment }\end{array}$ & $\begin{array}{c}\text { Injection Pressure, } \\
\mathrm{P}(\mathrm{MPa})\end{array}$ & $\begin{array}{c}\text { Injection Speed, } \\
\mathrm{S}(\mathrm{cc} / \mathrm{s})\end{array}$ & $\begin{array}{c}\text { Cooling Time, } \\
\mathrm{C}(\mathrm{s})\end{array}$ \\
\hline 1 & 30 & 15 & 20 \\
2 & 30 & 25 & 20 \\
3 & 30 & 35 & 20 \\
4 & 30 & 15 & 40 \\
5 & 30 & 25 & 40 \\
6 & 30 & 35 & 40 \\
7 & 40 & 15 & 20 \\
8 & 40 & 25 & 20 \\
9 & 40 & 35 & 20 \\
10 & 40 & 15 & 40 \\
11 & 40 & 25 & 40 \\
12 & 40 & 35 & 40 \\
\hline
\end{tabular}

\section{RESULTS AND DISCUSSION}

The PP-HA biocomposite samples were prepared using injection moulding method. The mechanical properties, especially the impact strength and fractured surface morphological properties of the composites were tested. Figures 4 (a) - (d) show the impact strength of PP and PP-HA biocomposites at various injection process parameters P30C20, P30C40, P40C20, and P40C40, respectively. In this chart, the injection speed was taken into account and injection pressure and cooling time maintained at constant parameters. The highest impact strength for PP was obtained at the injection speed of $35 \mathrm{cc} / \mathrm{sec}$, injection pressure of $30 \mathrm{MPa}$, and cooling time of 20 secs (S35P30C20) was recorded as $237.3 \mathrm{~J} / \mathrm{m}$. The impact strength was reduced to $195.0 \mathrm{~J} / \mathrm{m}$ after the incorporation of $1 \mathrm{wt} \% \mathrm{HA}$. The highest impact strength for PP-HA biocomposite was obtained at the injection speed of $15 \mathrm{cc} / \mathrm{sec}$, injection pressure of $30 \mathrm{MPa}$, and cooling time of $20 \mathrm{sec}$ (S15P30C20). The impact strength was recorded as $216.5 \mathrm{~J} / \mathrm{m}$. The impact strength of PP increased as the injection speed increased for P30C 20 and P40C20 experiments, whereas the impact strength reduced after $25 \mathrm{cc} / \mathrm{sec}$ for P40C20 experiment. Therefore, the optimum process parameter for PP was determined to be $25 \mathrm{cc} / \mathrm{sec}$ for $40 \mathrm{MPa} / 20 \mathrm{sec}$ experiment (S25P40C20). Scanning electron microscope (SEM) observation indicated that the biomimetic HA crystals were uniformly distributed in the PP matrix. As the HA content increased in the composite, the fracture mechanism of the composites changed from gliding fracture to gliding and brittle fracture.

Figure 5 shows the impact strength of PP and PP-HA biocomposites at various injection pressures, and constant injection speed and cooling time designated as S15C20sec, S15C40, S25C20, S25C40, S35C20, and S35C40, respectively. The injection pressure was taken into account with injection speed and cooling time maintained at constant parameters. The highest impact strength for PP was obtained at the injection speed of 35cc/sec, injection pressure of 30MPa and cooling time of $20 \mathrm{sec}$ (S35P30C20) was recorded as $228.3 \mathrm{~J} / \mathrm{m}$. The impact strength was reduced to $195.0 \mathrm{~J} / \mathrm{m}$ after incorporation of $1 \mathrm{wt} \%$ HA. The highest impact strength for PP-HA biocomposite was obtained at the injection speed of $15 \mathrm{cc} / \mathrm{sec}$, injection pressure of $30 \mathrm{MPa}$, and cooling time of $20 \mathrm{sec}(\mathrm{S} 15 \mathrm{P} 30 \mathrm{C} 20)$ and recorded as $216.5 \mathrm{~J} / \mathrm{m}$. 
$\leadsto$ PP at 30MPa, 20s $\leftrightharpoons$ PP-HA at 30MPa, 20s

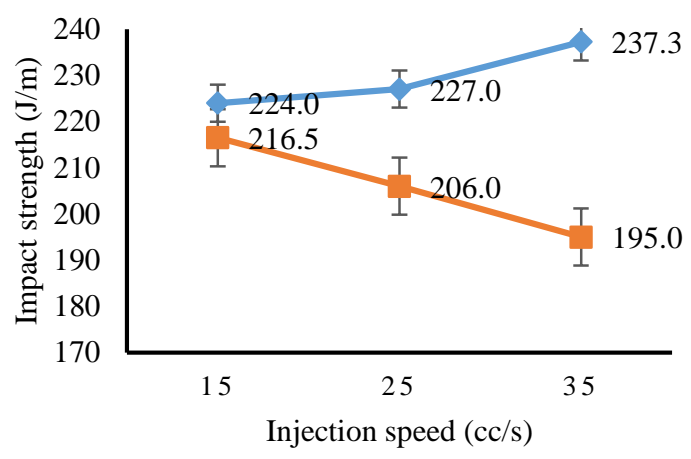

(a)

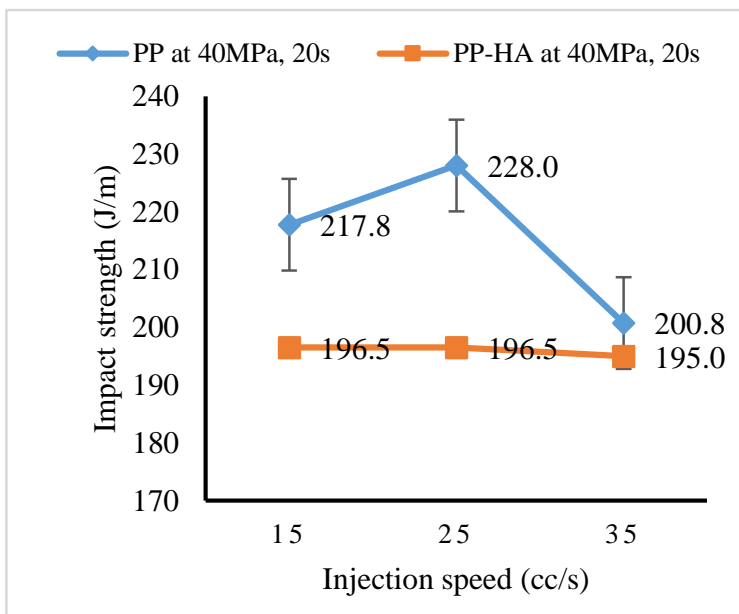

(c)

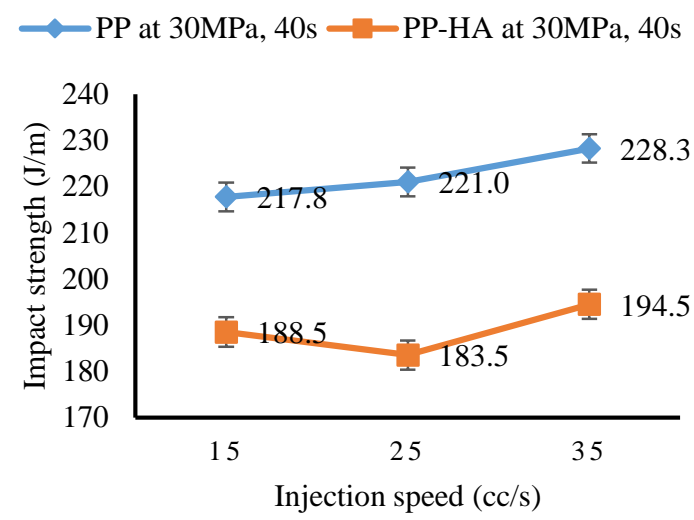

(b)

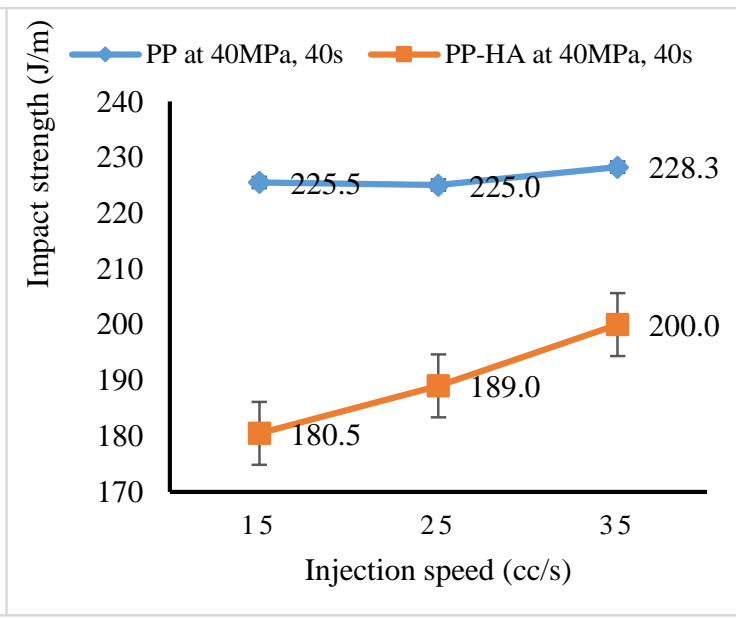

(d)

Figure 4. Effect of Injection Speed on Impact Strength of PP and PP-HA biocomposites (a) P30C20 (b) P30C40 (c) P40C20 (d) P40/C40.

Figures 6 (a)-(f) show the impact strength of PP and PP-HA biocomposites processed at various cooling times, and constant injection speed and injection pressure designated as S15P30, S15P40, S25P30, S25P40, S35P30, and S35P40, respectively. In this chart, the cooling time was taken into consideration as the interaction parameter with injection speed and pressure maintained at constant parameters. The highest impact strength for PP was obtained at the injection speed of $35 \mathrm{cc} / \mathrm{sec}$, injection pressure of $30 \mathrm{MPa}$, and cooling time of $20 \mathrm{sec}(\mathrm{S} 35 \mathrm{P} 30 \mathrm{C} 20)$ was recorded as $228.3 \mathrm{~J} / \mathrm{m}$. The impact strength was reduced to $195.0 \mathrm{~J} / \mathrm{m}$ after incorporation of $1 \mathrm{wt} \%$ HA. The highest impact strength for PP-HA biocomposite was obtained at the injection speed of $15 \mathrm{cc} / \mathrm{sec}$, injection pressure of $30 \mathrm{MPa}$, and cooling time of $20 \mathrm{sec}$ (S15P30C20). The impact strength was recorded as $216.5 \mathrm{~J} / \mathrm{m}$. 


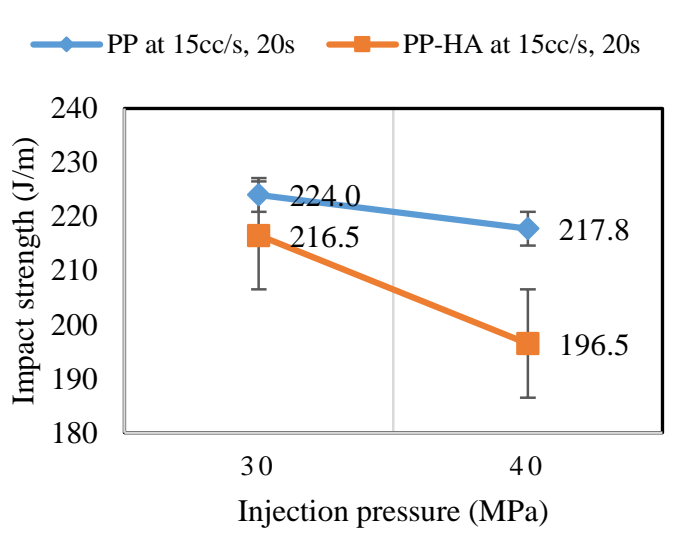

(a)

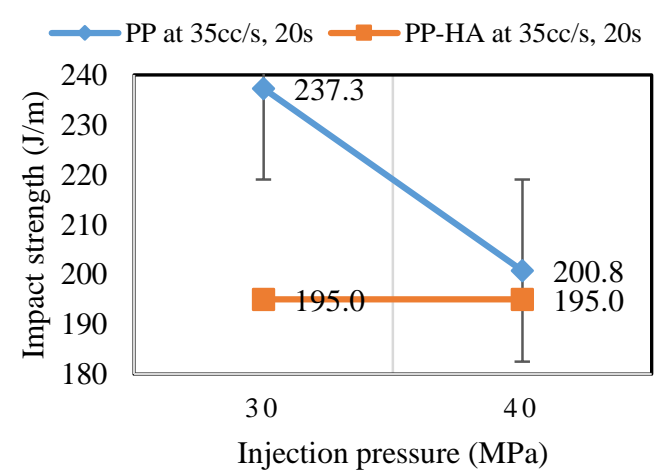

(c)

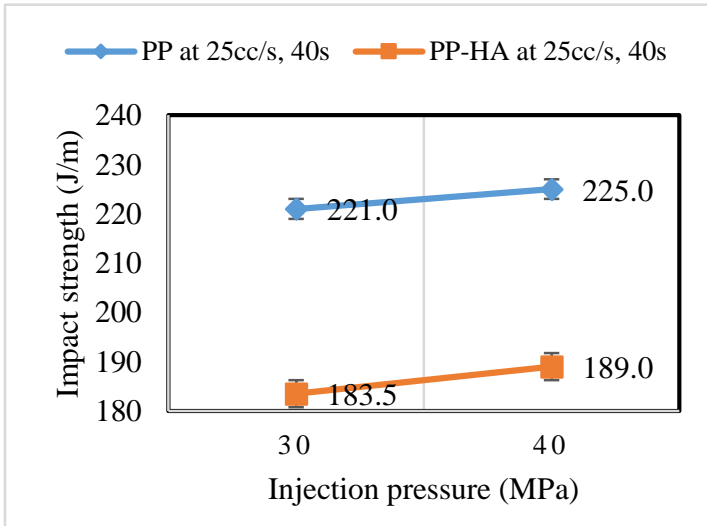

(e)

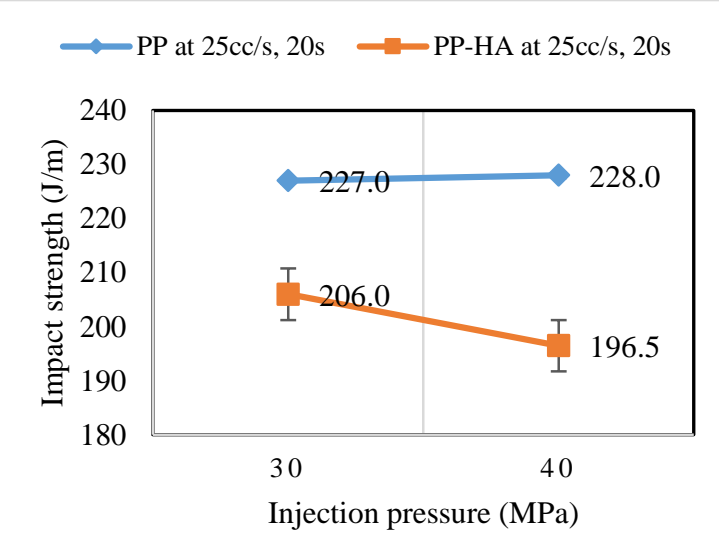

(b)

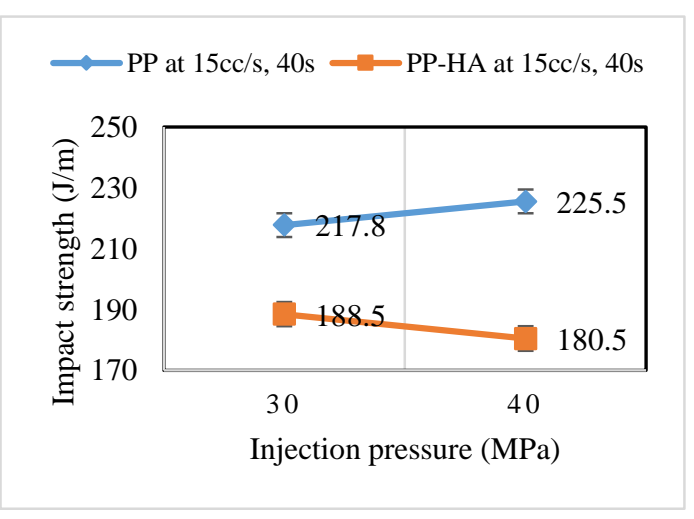

(d)

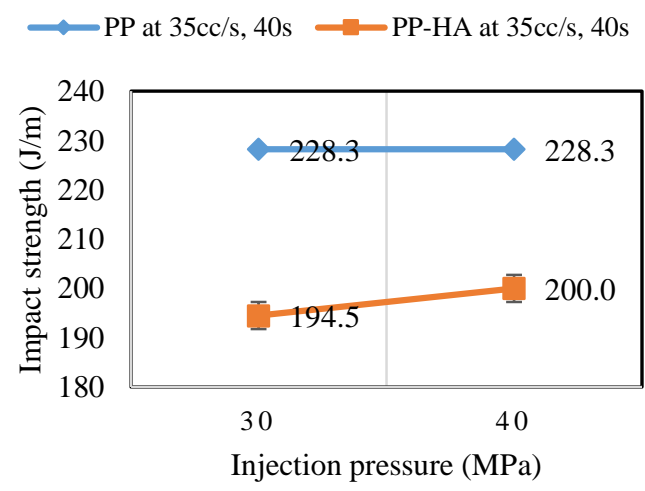

(f)

Figure 5. Effects of Injection Pressures on Impact Strength of PP and PP-HA biocomposites (a) S15C20 (b) S15C40 (c) S25C20 (d) S25C40 (e) S35C20 (f) S35C40

\section{Morphological Broperties of PP and PP-HA biocomposites}

In order to study the impact fracture mechanism of PP and PP-HA composites, the fracture morphology of the impact fractured samples was investigated using SEM analysis. The impact strength of the HA reinforced composites is influenced by many parameters including HA pullouts and degree of adhesion [16]. In the PP-HA composites, the HA with evenly distributed ratio leads to pullouts during fracture [17]. Figures 7(a) 
and (b) represent the SEM morphology of low impact strength of PP-HA biocomposite and high impact strength of PP-HA biocomposite, respectively.

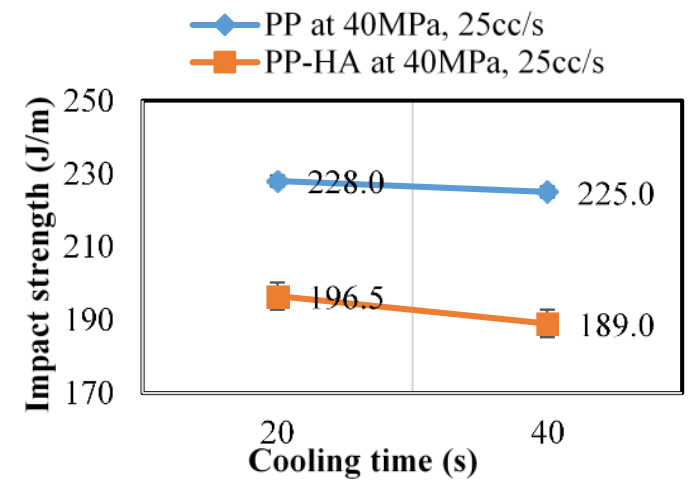

(a)

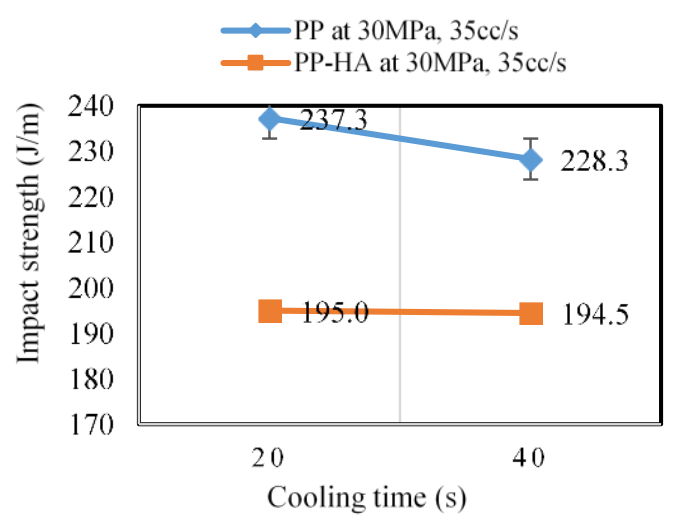

(c)

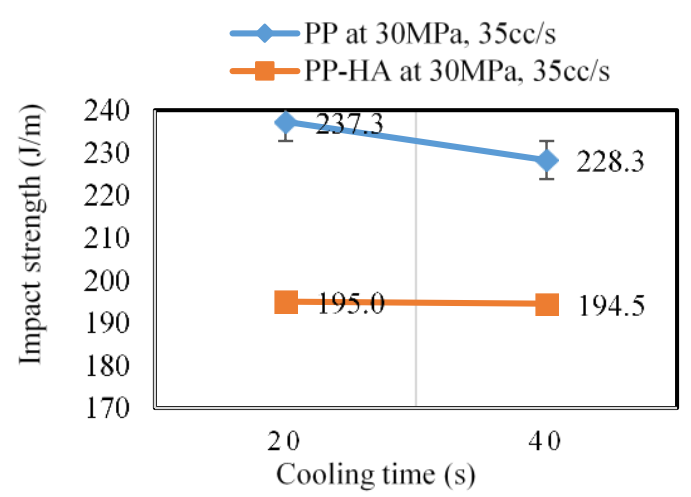

(e)

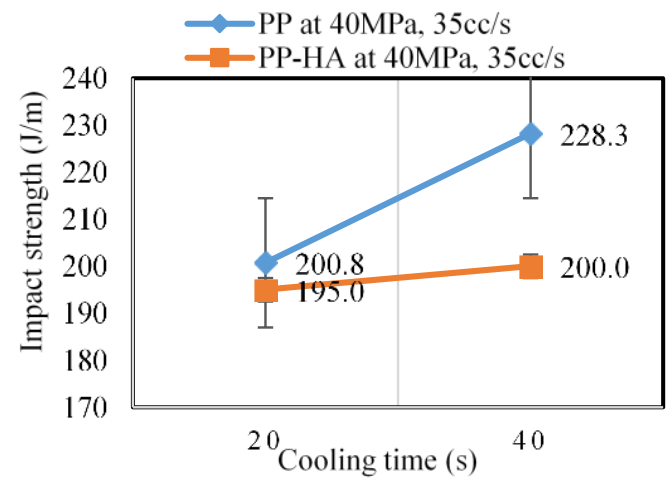

(b)

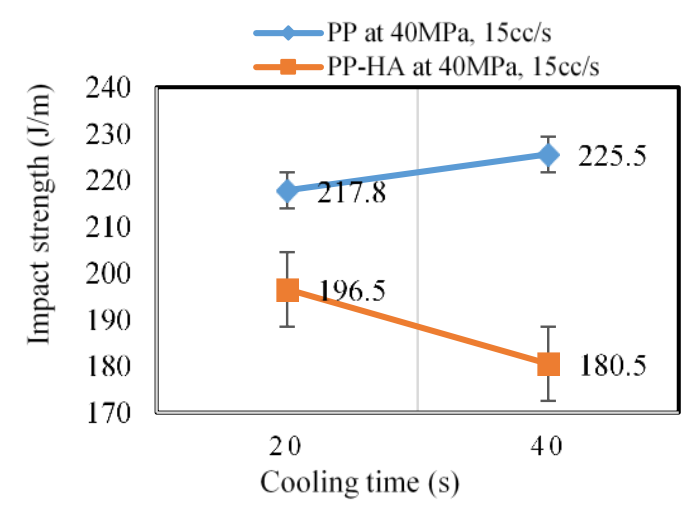

(d)

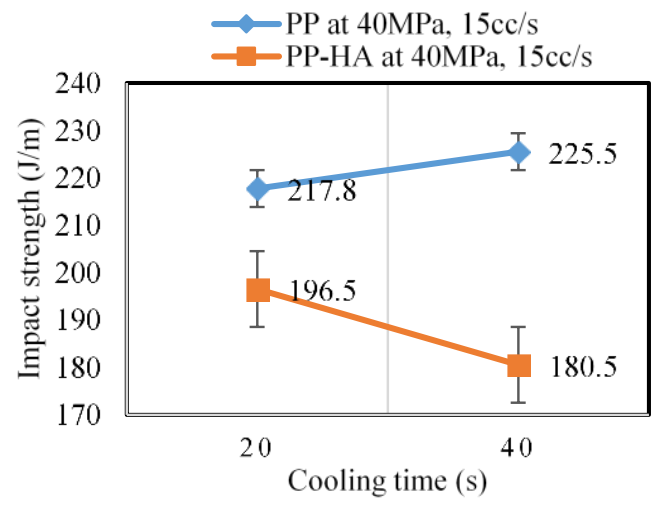

(f)

Figure 6. Effect of Cooling Time on Impact Strength of PP and PP-HA biocomposites (a) S15P30 (b) S15P40 (c) S25P30 (d) S25P40 (e) S35P30 (f) S35P40

The SEM micrographs of both composites indicate that the HA pullout mechanism and poor interfacial bonded regions played an eminent role during the impact fracture of the composites. There was a clear morphological difference witnessed in the composites of the high and low impact strength of PP-HA composites. The observed impact strength difference between Figures 7(a) and (b) was due to the distribution of HA 
nanoparticles and the bonding quality. In Figure 7(a), HA was unevenly distributed in the PP matrix, and poor bonding causing the most fractured surface along the interface between the PP matrix and n-HA. The fracture was brittle at the surface of the fracture. There were no HA pullouts witnessed. In Figure 7(b), there were HA pullouts witnessed along the fractured area. This may be due to the high HA distribution on the PP matrix and poor bonding causing the most fractured surface along the interface between the PP matrix and n-HA. Poor interconnections between the PP matrix and HA were observed by the presence of the debonding layer on the fractured surface. Figure 7(c) shows the SEM images of the fractured surfaces of pure PP which has the highest impact strength at different magnifications viz. x100, x250, and x500. There were no pullouts witnessed in the micrograph and it has a uniform rupture.

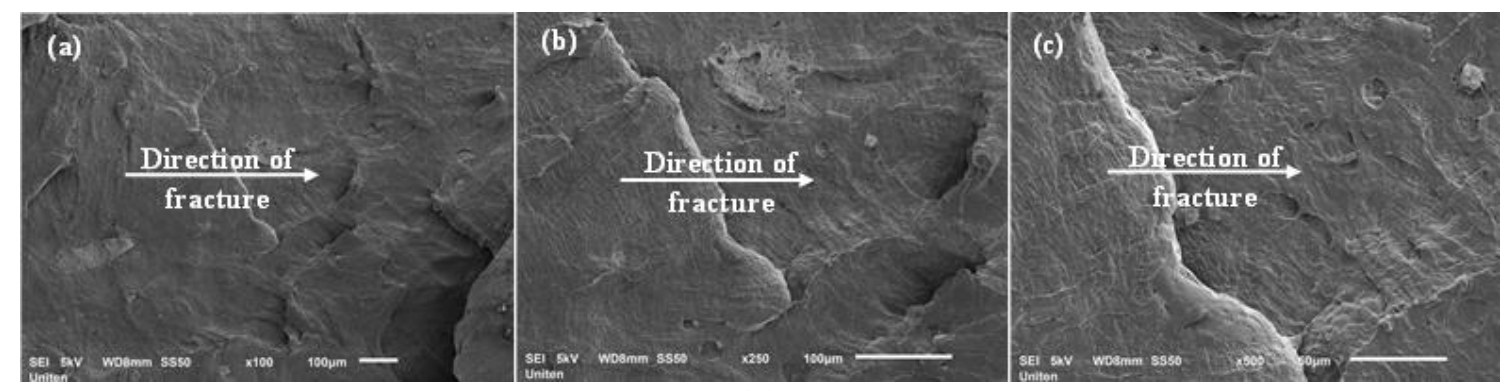

(a)

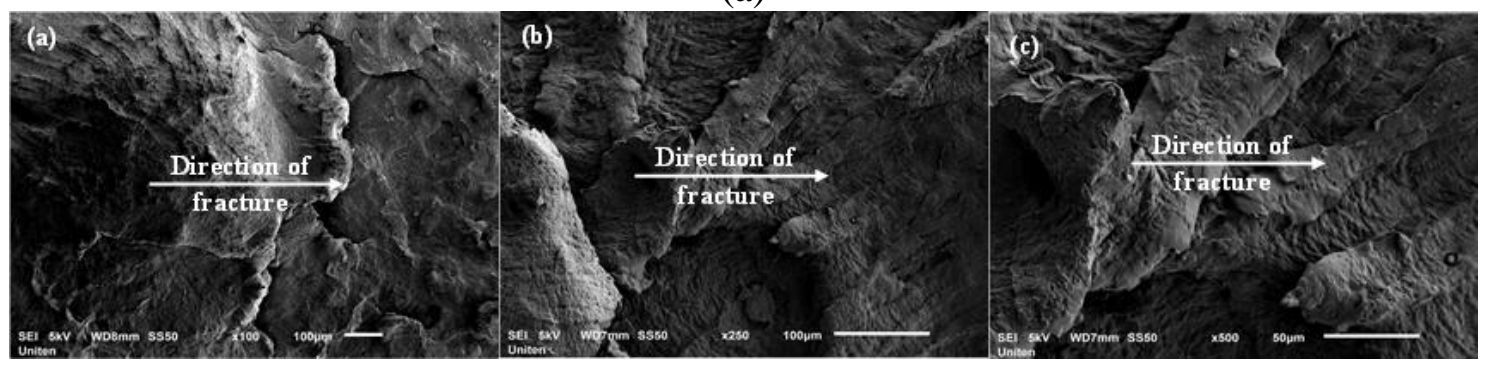

(b)

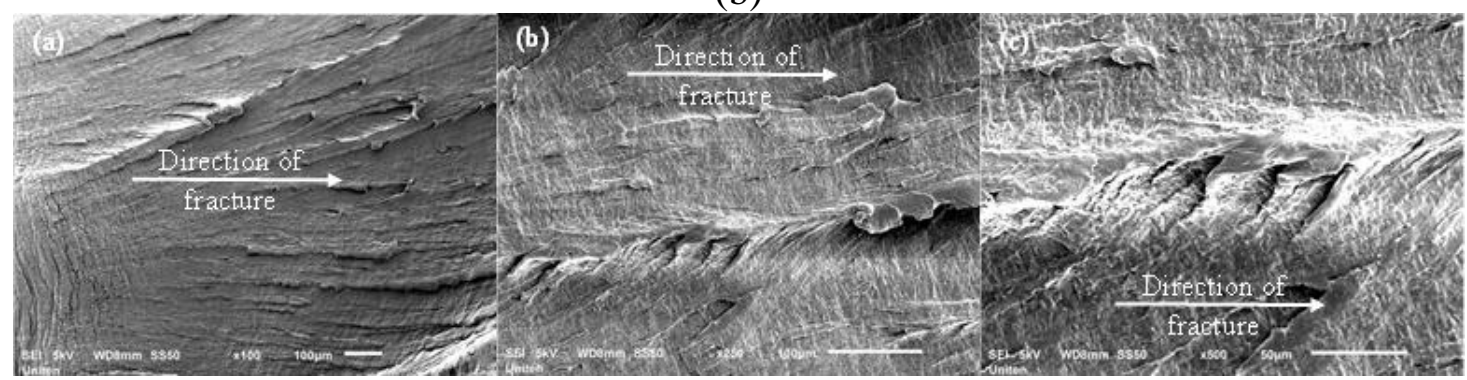

(c)

Figure 7. SEM images of fracture surfaces of PP-HA which has the (a) lowest impact strength, (b) highest impact strength and (c) pure PP which has the highest impact strength.

\section{CONCLUSIONS}

The investigation of the effects of pressure, speed, and cooling time on the mechanical properties of PP-HA composites leads to the following important results: 
i) HA can be used as a reinforcing bio-filler for thermoplastics such as PP. The impact strength of the PP-HA (99/1 w/w\%) nanocomposite was reduced with the addition of HA. This is a common observation in most of the particulate filled composites.

ii) The increasing pressure increases the strength of the composites while it has no significant effect on the impact resistance of the composites. Because the increase in pressure enhances mechanical bonding and locking of HA particle surfaces and $\mathrm{PP}$ in the composites, it causes an increase in impact resistance of the composite. On the other side, an increase in pressure causes a decrease the strength of PP. The influence of these synchronic opposite factors caused little changes in the impact resistance of composites.

iii) The impact strength of the PP-HA composite was considerably reduced after the incorporation of HA nano fillers into the PP matrix. The highest impact strength for PP-HA from the test specimen was determined to be $216.5 \mathrm{~J} / \mathrm{m}$ obtained from the process parameters of value $30 \mathrm{MPa}, 15 \mathrm{cc} / \mathrm{s}$, and $20 \mathrm{~s}$ which correspond to injection pressure and speed and cooling time, respectively.

iv) Increasing pressure and cooling time do not have significant effects on the mechanical properties of PP reinforced with HA. This phenomenon can be related to the good strength of PP-HA interface, the decrease of HA agglomeration, and the number of voids and porosities in these composites caused by a using silane coupling agent. The single noticeable effect of the increase in pressure and cooling time on these composites was the increase of transformation of PP structure from amorphous to crystalline.

v) The best conditions to produce composites of optimum mechanical properties were injection pressure of $30 \mathrm{MPa}$, injection speed of $15 \mathrm{cc} / \mathrm{s}$, and cooling time of $20 \mathrm{~s}$ for PP-HA biocomposite.

vi) The analyses presented in this study were geared towards making informed decisions on the compromises of several performance measures. It is known that characterising the efficient solutions is an important way to realise the potential of an injection moulding operation. Besides that, by applying all varying parameters, we are most definitely able to reduce time of a real time injection moulding operation and produce a better quality product.

vii) Further studies could be performed by maximizing more number of variables as well as levels and developing a mathematical model using statistical software for impact strength.

\section{ACKNOWLEDGMENTS}

Authors would like to thank the faculty and Management of UNITEN for providing facilities for undergoing this research. This project was not associated with and research grant.

\section{REFERENCES}

[1] Lee TS, W.A.W.A. Rahman, A.R. Rahmat, Tiam TT, Soo TB, Low CY. Computer aided injection moulding process analysis of polyvinyl alcohol-starch green biodegradable polymer compound. Journal of Manufacturing Processes. 2012;14:8-19.

[2] Erfan O, Behzad SH, Seyed MD, Mozhgan B, Saeed D, Iman H, et al. Warpage and shrinkage optimization of injection-molded plastic spoon parts for 
biodegradable polymers using taguchi, ANOVA and artificial neural network methods. Journal of Materials Science \& Technology. 2016;32:710-20.

[3] Ries Rue L, Cuhna Antonio M, Oliveira Maria J, Compos Ana R, Bevis MJ. Relationship between processing and mechanical properties of injection molded high molecular mass polyethylene+ hydroxyapatite composites. Materials Research Innovations. 2001;4:263-72.

[4] Homaeigohar SSh, Yari Sadi A, Javadpour J, Khavandi A. The effect of reinforcement volume fraction and particle size on the mechanical properties of $\beta$-tricalcium phosphate-high density polyethylene composites. J Eur Ceram Soc. 2006;26:273-8.

[5] Fang LM, Gao P, Leng Y. High strength and bioactive hydroxyapatite nanoparticles reinforced ultrahigh molecular weight polyethylene. Compos Pt B. 2007;38:345-51.

[6] Fang LM, Leng Y, Gao P. Processing and mechanical properties of HA/UHMWPE nanocomposites. Biomaterials. 2006;27:3701-7.

[7] Campbell, GA, Campbell SE, Bullwinkel M, Savoka J, Ragona L, et al. Effect of oil additives and injection molding process parameters on the tensile and impact energy of polypropylene. Proceedings, 59th Annual Technical Conference of the Society of Plastics Engineers2001. p. 466-70.

[8] Jie Z, Joseph CC, E. Daniel K. Tensile Strength and Optimization of Injection Molding Processing Parameters Using the Taguchi Method. Spring. 2004;4:2.

[9] Alvarez V, Vazquez A, Bernal C. Effect of microstructure on the tensile and fracture properties of sisal fiber/starch-based composites. Journal of Composite Materials 2006;40(1):21-35..

[10] Wang M, Deb S, Bonfield W. Chemically coupled hydroxyapatite-polyethylene composites: processing and characterisation. Mater Lett. 2000;44:119-24.

[11] Bonner M, Ward M, McGregor W, Tanner KE, Bonfield W. HA/PP composite: a novel bone substitute material. J Mater Sci Lett. 2001;20:2049-51.

[12] Cunha AM, Reis RL, Ferreira FG, Granja PL. The Influence of Processing Conditions on the Mechanical Behaviour of UHMWPE/HA and PMMA/HA Composites. Kluwer Academic Publishers; 1995. p. 163-76.

[13] Unwin AP, Ward IM, Ukleja P, Weng J. The role of pressure annealing in improving the stiffness of polyethylene/hydroxyapatite composites. Journal of Materials Science. 2001;36:3165-77.

[14] Tjong SC, Xu SA, Mai YW. Impact fracture toughness of short glass fiberreinforced polyamide 6,6 hybrid composites containing elastomer particles using essential work of fracture concept. Materials Science and Engineering: A. 2003;347:338-45.

[15] Ramsteiner F, Theysohn R. Tensile and impact strengths of unidirectional, short fibre-reinforced thermoplastics. Composites. 1979;10:111-9.

[16] Rajendran M, Manjusri M, Fantanhun D, Amar KM. Influence of processing parameters on the impact strength of biocomposites: A statistical approach. Composites Part A: Applied Science and Manufacturing. 2016;83:120-9.

[17] Saheb DN, Jog JP. Natural fiber polymer composites: a review. Advances in Polymer Technology. 1999;18:351-63. 